\title{
Experimental Investigation of a Gyroscopic Vibration Absorber For Vibration Control of a Vertical Cantilever Beam
}

\author{
[ F. Ünker, O. Çuvalcı ]
}

\begin{abstract}
Taking advantage of the angular momentum of the rotating gyroscope, gyrostabilizer systems are expected to become more widely actualized as they provide an effective means of motion control with several significant advantages for various structures. In this paper, a system of the gyroscope coupled via the massless torsional spring and the massless torsional damper mounted on the tip mass of a beam subjected to a vibrating base is considered.

On the other hand, the effect of the angular velocity of the gyroscope is studied, and it is shown that the angular velocity (spin velocity) of a gyroscope has a significant effect on the behavior of the dynamic motion. Correctness of the numerical results is verified by experimental simulations.
\end{abstract}

Keywords - gyrostabilizer, damping, vibration control, gyroscopic vibration absorber

\section{Introduction}

The attenuation of vibration caused by dynamic effects is desired in many engineering fields. To reduce or eliminate the undesirable motions, various types of structural control theories have been developed and evolved for different dynamic loads, and quite a few of them have been potentially practically useful. Structural control methods can be classified as passive, active, and semi-active control methods according to their energy consumption (Datta T.K. 2003 and Housner et al 1997). In the last decades, different types of structural control devices have been investigated for the possibility of using active, and semiactive control methods to develop the control forces upon passive approaches for mitigating structural responses (Soong 1990; Spencer and Sain 1997; Housner et al. 1997; Kobori et al. 2003; Soong and Spencer 2002; Spencer 2002). However, the passive control method is activated by the structural motion without requiring external force or energy to reduce structural responses, and utilizes the motion of the structure at the location of the device (Soong and Dargush 1997). Active control method requires considerable amount of external power to operate actuators that supply a control force to the structure. Due to requiring sensors and evaluator / controller equipments, active control devices are more complex, and, furthermore they do not have reliability, low cost, and robustness compared to passive control techniques (Soong and Spencer 2002). On the other hand,

the active control is able to adapt to structural changes and to varying loading conditions.

\section{F.Ünker}

Gümüşhane Universty

Turkey

\section{O. Çuvalcı}

Karadeniz Technical University

Turkey

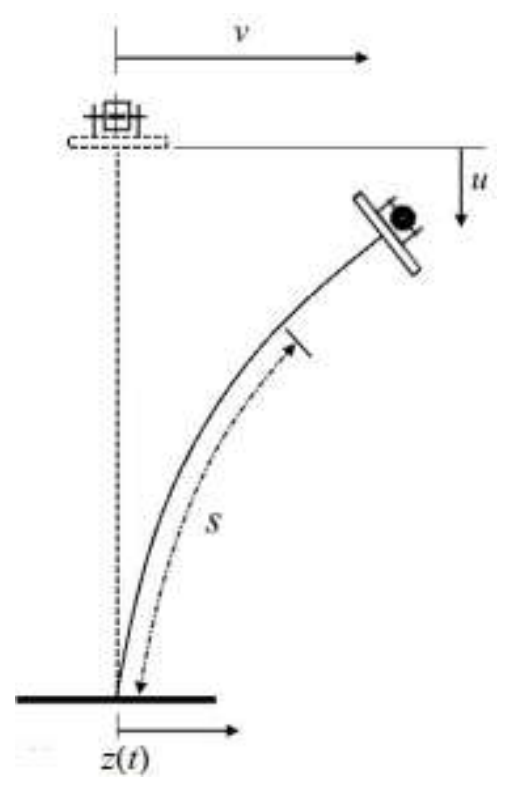

Fig. 1. Cantilever model with end mass, gyroscope, and vertical base excitation.

The gyroscopic moment induced by a rotating object offers attractive means to protect structures against natural hazards in various ways. The engineering community have developed various stabilizer systems as a means for mitigating the effects of dynamic loading on structures. The use of gyrostabilizers has emerged, as they have an ability to control vibration at low frequency, represent a weight and volume saving, and, furthermore, the stored kinetic energy can provide emergency power (Townsend et al. 2007; Thornton et al. 2005; Perez and Steinmann 2009). For roll reduction, Dr. Otto Schlick carried out such a device that has a high speed rotating disk at a constant speed and yields producing a resistive gyroscopic torque as a source of angular momentum (Schlick, 1904a, b). The mechanism does not require any other external source of energy, in which the rotor speed is produced by an electric motor in a rotating gimbal. Therefore, this can be classified as a passive control device in a variation of passive vibration control 
systems. The gyrostabilizer is effective for bending moments rather than shear forces, because the gyrostabilizer utilizes the gyroscopic moment to reduce or eliminate the undesirable motions. Consequently this paper considers the motion of a symmetric gyro with coupling to the free end of a beam subjected to a harmonic base excitation, which is supported with a torsional spring and damper. Correctness of the numerical results is verified by experimental simulations. The comparison with the results shows that the equations of motion are very accurate.

\section{Passive Gyroscopic Absorber}

Fig. 1 shows the beam as a vertical cantilever of length $\mathrm{L}$ with an end mass Mt to which an additional gyro system is attached at the free end and subjected to a harmonic base excitation at the other end of the beam. The horizontal displacement of base is $\mathrm{z}$. The beam is assumed to be initially straight, of length $\mathrm{L}$, with moment of inertia It, at a position $\mathrm{L}$ from the free end of the beam. The horizontal and vertical elastic displacements at the free end are $\mathrm{v}$ and $\mathrm{u}$, respectively. Due to elastic deformation of the beam, $s$ represents the distance along arc-length of the beam.

\section{A. Equations of Motion of the Gyro- Beam System}

Equations of the beam and gyro have been expressed in Ref. (Ünker F, and Çuvalcı O. ) (see Eqs. (16) and (17)) as follows, respectively;

$$
\begin{aligned}
& \left\{\begin{array}{c}
\rho A G_{1}+m+M_{t}+I_{t} G_{5}{ }^{2}+\left(\rho A G_{3}+\left(m+M_{t}\right) G_{4}{ }^{2}+I_{t} G_{5}{ }^{4}\right) v^{2}+\frac{1}{4} I_{t} G_{5}{ }^{6} v^{4} \\
+\left(G_{5}+\frac{1}{2} v^{2} G_{5}{ }^{3}\right)^{2}\left[I_{o}(\cos \theta)^{2}+I_{p}(\sin \theta)^{2}\right]
\end{array}\right\} \ddot{v} \\
& +\left[\rho A G_{3}+\left(m+M_{t}\right) G_{4}{ }^{2}+I_{t} G_{5}{ }^{4}+\frac{1}{2} I_{t} G_{5}{ }^{6} v^{2}\right] v \dot{v}^{2}+\left[E I G_{6}-\rho A g G_{9}-\left(m+M_{t}\right) g G_{4}+2 E I G_{7} v^{2}+\frac{3}{4} E I G_{8} v^{4}\right] v \\
& +\left(G_{5}+\frac{1}{2} v^{2} G_{5}{ }^{3}\right)\left[\begin{array}{c}
\left(I_{p}-I_{0}\right)\left(\dot{v} G_{5}+\frac{1}{2} v^{2} \dot{v} G_{5}{ }^{3}\right) \dot{\theta} \sin 2 \theta \\
+I_{o}\left(v \dot{v}^{2} G_{5}{ }^{3}\right)(\cos \theta)^{2} \\
+I_{p}\left(v \dot{v}^{2} G_{5}{ }^{3}\right)(\sin \theta)^{2} \\
+I_{p} \Omega \dot{\theta} \cos \theta
\end{array}\right]=-\left(\rho A G_{2}+m+M_{t}\right) \ddot{z} \\
& I_{0} \ddot{\theta}-\frac{1}{2}\left(I_{p}-I_{0}\right)\left(\dot{v} G_{5}+\frac{1}{2} v^{2} \dot{v} G_{5}{ }^{3}\right)^{2} \sin 2 \theta-I_{p} \Omega\left(\dot{v} G_{5}+\frac{1}{2} v^{2} \dot{v} G_{5}{ }^{3}\right) \cos \theta+c \dot{\theta}+k \theta=0
\end{aligned}
$$

After the rearrangement, Eq.(1) becomes

$$
\begin{aligned}
& \left\{\begin{array}{c}
\alpha_{1}+\alpha_{2} v^{2}+\alpha_{3} v^{4} \\
+\left(G_{5}+\frac{1}{2} v^{2} G_{5}{ }^{3}\right)^{2}\left[I_{o}(\cos \theta)^{2}+I_{p}(\sin \theta)^{2}\right]
\end{array}\right\} \ddot{v} \\
& +\left\{\alpha_{2}+2 \alpha_{3} v^{2}+G_{5}{ }^{3}\left(G_{5}+\frac{1}{2} v^{2} G_{5}{ }^{3}\right)\left[I_{o}(\cos \theta)^{2}+I_{p}(\sin \theta)^{2}\right]\right\} v \dot{v}^{2}+\left[\alpha_{4}+\alpha_{5} v^{2}+\alpha_{6} v^{4}\right] v \\
& +\left(G_{5}+\frac{1}{2} v^{2} G_{5}{ }^{3}\right)\left[\left(I_{p}-I_{0}\right) \dot{v}\left(G_{5}+\frac{1}{2} v^{2} G_{5}{ }^{3}\right) \dot{\theta} \sin 2 \theta+I_{p} \Omega \dot{\theta} \cos \theta\right]=-\gamma \ddot{z}
\end{aligned}
$$

in which

$$
\begin{aligned}
& \alpha_{1}=\rho A G_{1}+m+M_{t}+I_{t} G_{5}{ }^{2} \\
& \alpha_{2}=\rho A G_{3}+\left(m+M_{t}\right) G_{4}{ }^{2}+I_{t} G_{5}{ }^{4} \\
& \alpha_{3}=\frac{1}{4} I_{t} G_{5}{ }^{6} \\
& \alpha_{4}=E I G_{6}-\rho A g G_{9}-\left(m+M_{t}\right) g G_{4} \\
& \alpha_{5}=2 E I G_{7} \\
& \alpha_{6}=\frac{3}{4} E I G_{8} \\
& \gamma=\left(\rho A G_{2}+m+M_{t}\right)
\end{aligned}
$$

\section{B. Gyroscopic Absorber Design}

The gyro system consists of a disk mass m, which can spin freely about its geometric axis (gimbal) mounted to the tip mass of the beam as shown in Fig. 2. The disk mass, $m$ of gyro at free end is assumed to have angular speed $\Omega$, and the rotation of the gimbal of this disk is also resisted by torsional spring and damping torque defined by $k \theta$ and $c \dot{\theta}$, respectively. 


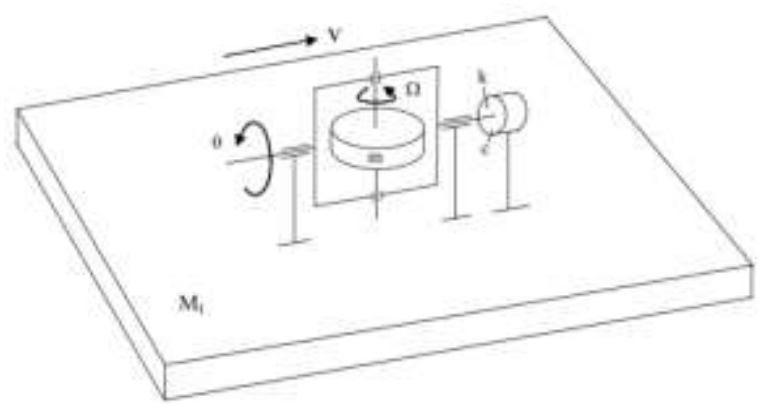

Fig. 2. Gyro model with end mass $\mathrm{M}_{\mathrm{t}}$, massless torsional spring and damper.

Table 1: Physical properties of the system

\begin{tabular}{|c|c|c|}
\hline Symbol & Numerical values & Description \\
\hline $\mathrm{E}$ & $210 \times 10^{9} \mathrm{~N} / \mathrm{m}^{2}$ & Young's modulus \\
\hline $\mathrm{h}$ & $6 \mathrm{~mm}$ & beam thickness \\
\hline $\mathrm{b}$ & $30 \mathrm{~mm}$ & beam width \\
\hline $\mathrm{L}$ & $1.17 \mathrm{~m}$ & length of the beam \\
\hline$\rho$ & $7850 \mathrm{~kg} / \mathrm{m}^{3}$ & density of the beam \\
\hline $\mathrm{M}_{\mathrm{t}}$ & $2.3 \mathrm{~kg}$ & tip mass \\
\hline $\mathrm{I}_{\mathrm{t}} / \mathrm{M}_{\mathrm{t}}$ & $3.34 \times 10^{-3} \mathrm{~m}^{2}$ & $\begin{array}{l}\text { ratio of tip mass moment of } \\
\text { inertia }\end{array}$ \\
\hline$I_{t}$ & $7.682 \times 10^{-3} \mathrm{~kg} \cdot \mathrm{m}^{2}$ & tip mass moment of inertia \\
\hline I & $5.4 \times 10^{-10} \mathrm{~m}^{4}$ & geometrical moment of inertia \\
\hline $\mathrm{g}$ & $9.81 \mathrm{~m} / \mathrm{s}^{2}$ & gravitational acceleration \\
\hline $\mathrm{A}=\mathrm{b} . \mathrm{h}$ & $1.8 \times 10^{-4} \mathrm{~m}^{2}$ & area of cross section \\
\hline $\mathrm{c}$ & 0.002 N.m.s/rad & $\begin{array}{l}\text { Torsion damping coefficient of } \\
\text { gyro }\end{array}$ \\
\hline $\mathrm{k}$ & 0.04 N.m $/ \mathrm{rad}$ & $\begin{array}{l}\text { stiffness of torsion spring of } \\
\text { gyro }\end{array}$ \\
\hline$c_{t}$ & $0.6 \mathrm{~N} . \mathrm{s} / \mathrm{m}$ & $\begin{array}{l}\text { damping onto the tip of the } \\
\text { beam }\end{array}$ \\
\hline $\mathrm{m}$ & $0.1 \mathrm{~kg}$ & disk mass of gyroscope \\
\hline r & $0.05 \mathrm{~m}$ & radius of disk \\
\hline $\mathrm{I}_{\mathrm{p}}=\mathrm{m} \cdot \mathrm{r}^{2} / 2$ & $1.875 \times 10^{-4} \mathrm{~kg} \cdot \mathrm{m}^{2}$ & rotary inertia of disk \\
\hline $\mathrm{I}_{0}=\mathrm{I}_{\mathrm{p}} / 2$ & $9.375 \times 10^{-5} \mathrm{~kg} \cdot \mathrm{m}^{2}$ & mass moment of inertia of disk \\
\hline$\Omega$ & $0-15000 \mathrm{rpm}$ & rotating speed of disk \\
\hline
\end{tabular}

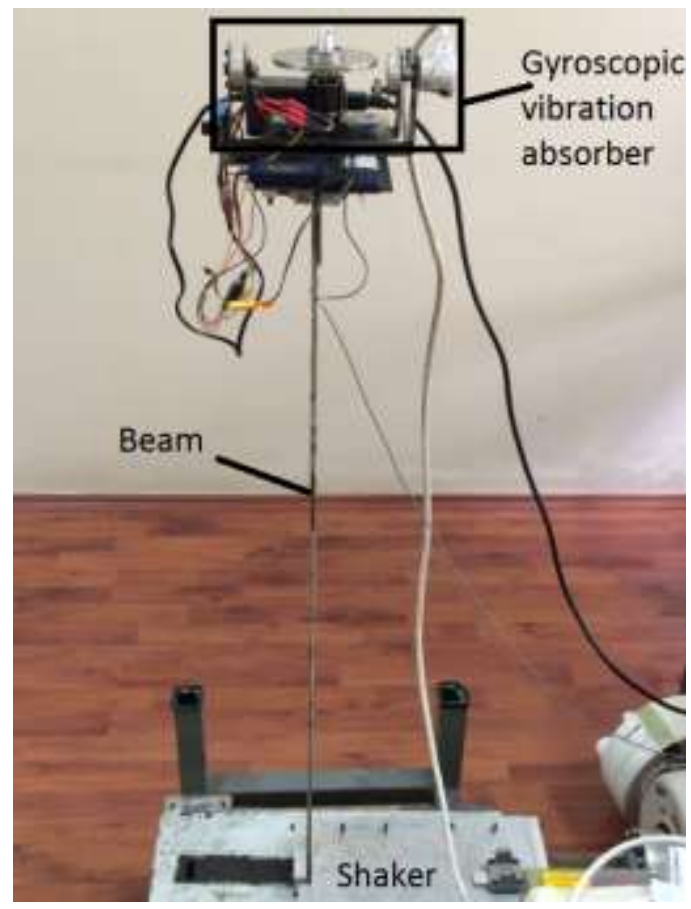

Fig. 3. Experimental Gyro-Beam Model

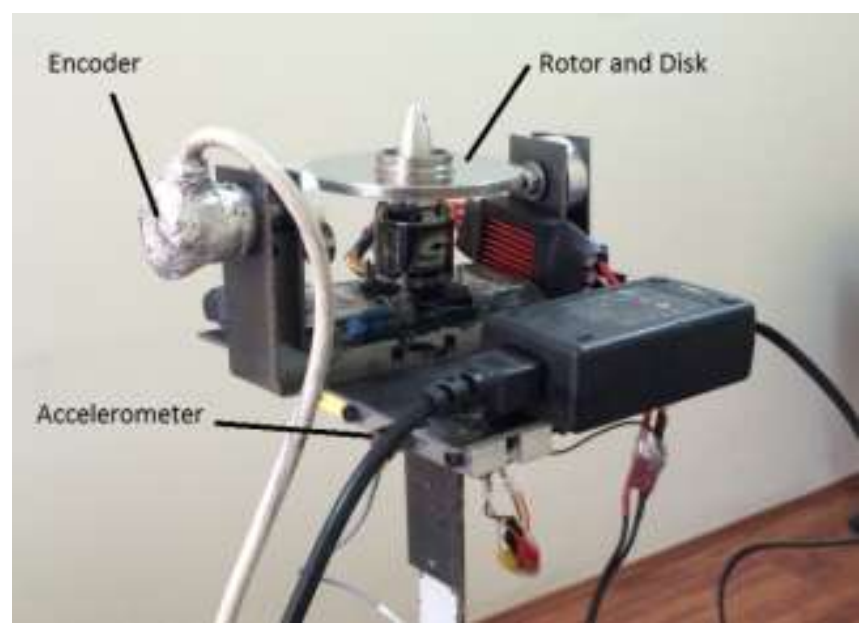

Fig. 4. Experimental Gyroscope Model

\section{Results and Discussion}

In the following calculations, a rectangle-cross beam is considered with thickness $\mathrm{h}=6 \mathrm{~mm}$, width $\mathrm{b}=30 \mathrm{~mm}$, length $\mathrm{L}=0.95 \mathrm{~m}$, density $\rho=7850 \mathrm{~kg} / \mathrm{m} 3$, and Young's modulus along the axial direction $\mathrm{E}=210 \times 10^{9} \mathrm{~N} / \mathrm{m}^{2}$. Eqs. (1) and (2) may be solved by using a Matlab software tool that involves the fourth-order Runge-Kutta method. The parameters of the numerical example are given in Table 1. In order to identify the dynamical behavior, the frequency response is simulated, with the time step size of $0.01 \mathrm{~s}$, and zero initial conditions.

\section{A. Numerical Simulations}

Figures 5 represents the frequency response curves of the beam at the free end for the different disk velocities. It demonstrates that the displacement responses of the beam can be considerably reduced when the disk speed is increased. The gyro reduces the maximum top displacement of beam by $100 \%$ by using the disk speed of $\Omega=15000$ $\mathrm{rpm}$. As seen from the figure, the moment of inertia of gyro has the possibility to reduce the vibration by increasing rotating speed $\Omega$ of disk. 
Proc. of the Fourth Intl. Conf. Advances in Civil, Structural and Mechanical Engineering- CSM 2016

Copyright (C) Institute of Research Engineers and Doctors, USA .All rights reserved.

ISBN: 978-1-63248-093-4 doi: 10.15224/ 978-1-63248-093-4-74

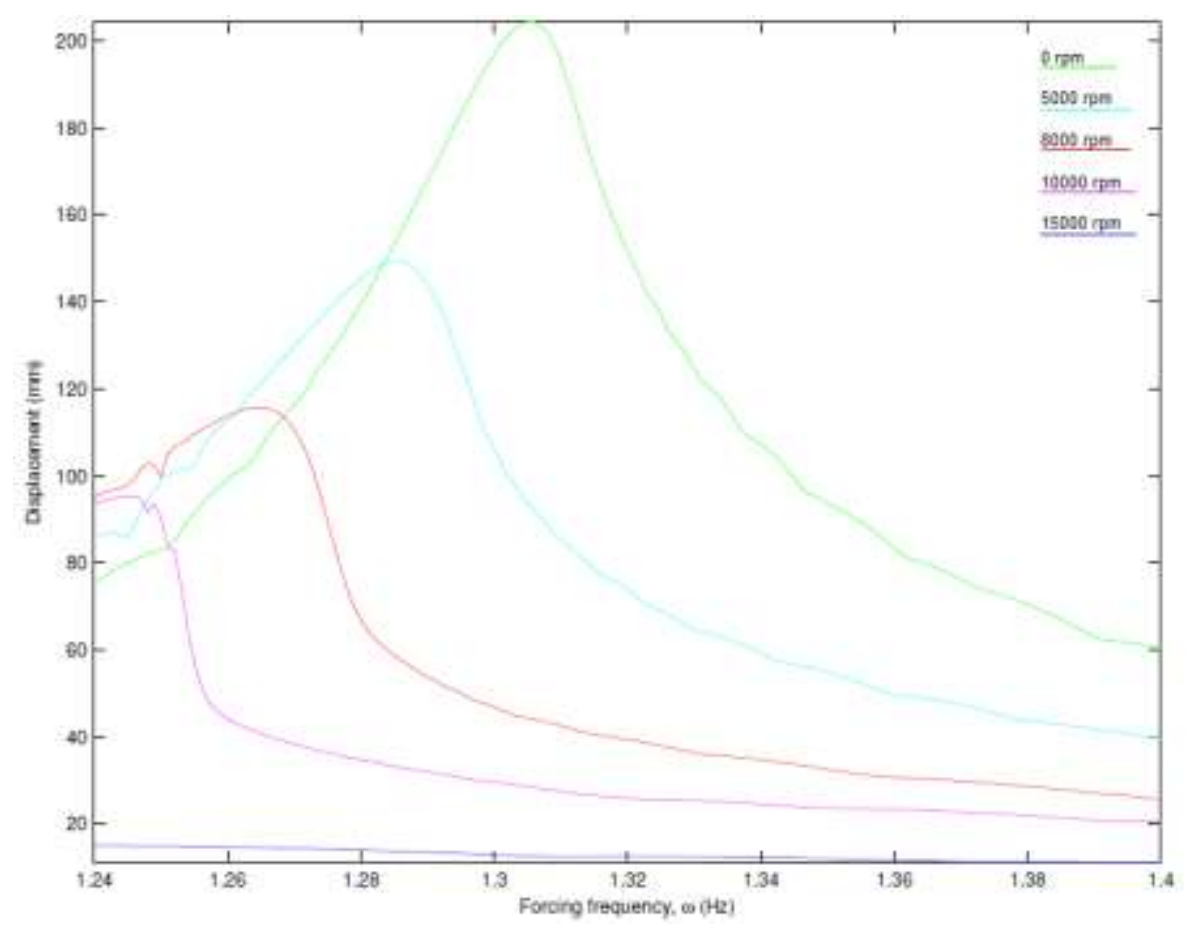

Fig.5. Theoretical frequency response curves of the tip mass for different rotational disk speeds of gyro with the base excitation of $\mathrm{z}=0.005 \cos (\omega \mathrm{t})$. (Sweep Rate: $0.001 \mathrm{~Hz} / \mathrm{Second}$ and Sweep Type : Linear, $\mathrm{z}_{0}=5 \mathrm{~mm}$ )

\section{B. Experimental Results}

A Brüel \& Kjaer / LDS CometUSB vibration control system was used to examine the frequency responses of the cantilever beam. The controller was setted for Sweep Rate: $0.001 \mathrm{~Hz} / \mathrm{Second}$ and Linear Sweep Type. Simulated frequency response curves of Figure 5 agree with measured frequency response curves of Figure 6.

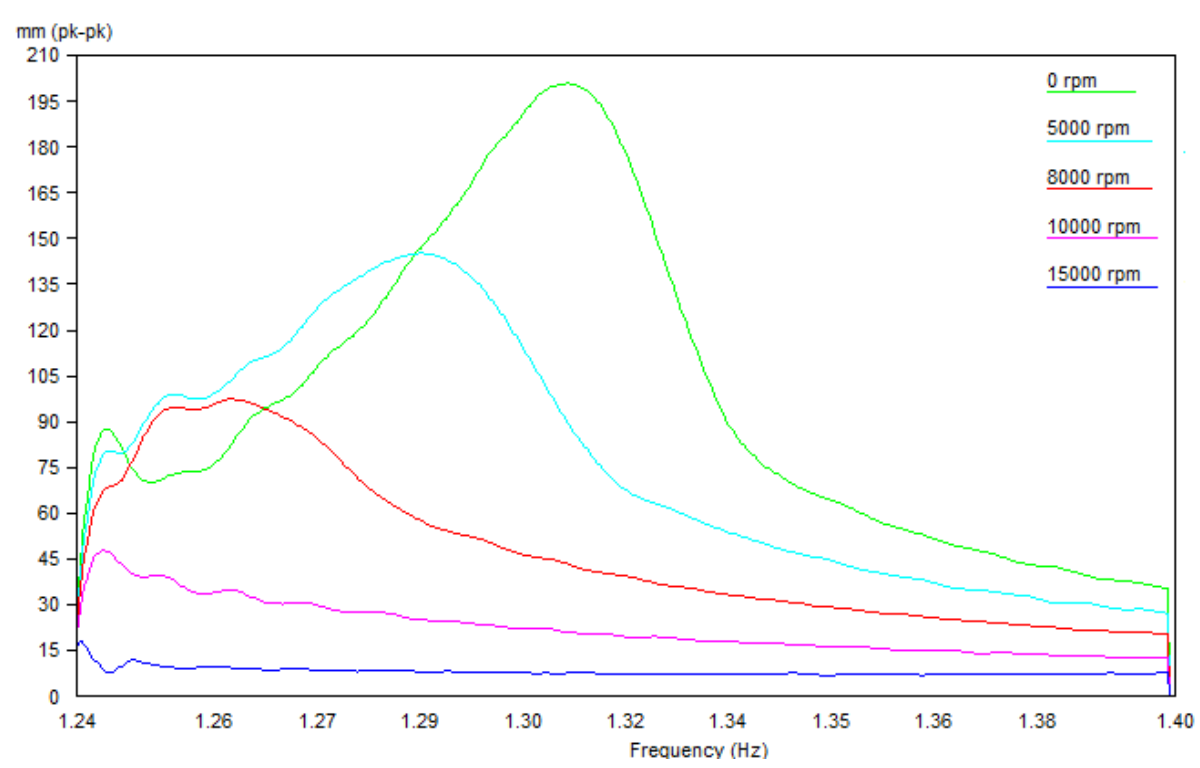

Fig.6. Experimental frequency response curves of the tip mass for different rotational disk speeds of gyro with the base excitation of $z=0.005 \cos (\omega t)$. (Sweep Rate: $0.001 \mathrm{~Hz} / \mathrm{Second}$ and Sweep Type : Linear, $\mathrm{z}_{0}=5 \mathrm{~mm}$ ) 


\section{Conclusion}

The results presented in these figures all indicate that the gyro system has significantly reduced the vibration of beam at free end by increasing rotating speed $\Omega$ of disk of gyro. The effectiveness is presented by computer simulations and the numerical results agree with the experimental solutions. From the consistency of the present study, the following conclusions is found:

- The rotary inertia of the rotor can be reduced by increasing rotor speed, which is proportion to the mass of disk. Thus, the weight and volume of the system can be reduced. The rotor speed for this gyrostabilizer is so effective that this system is more adaptable and has smaller mass than other conventional control devices with the same ability to be employed for vibration control.

\section{Acknowledgment}

This study was supported by the Scientific and Technological Research Council of Turkey (TUBITAK) under Grant no: 114M760.

\section{References}

[1] Datta T.K. (2003). "A state-of -the-art review on active control of structures”, ISET Journal of Earthquake Technology, Paper No. 430, 40(1),1-17.

[2] Housner, G. W., Bergman, L. A., Caughey, T. K., Chassiakos, A. G., Claus, R. O., Masri, S. F., Skelton, R. E., Soong, T. T., Spencer, B. F., and Yao, J. T. P. (1997). "Structural control: past, present and future", Journal of Engineering Mechanics, 123 (9), 897-971.

[3] Kobori, T. (2003). "Past, present and future in seismic response control in civil engineering structures." Proc., 3rd World Conf. on Structural Control, Wiley, New York, 9-14.

[4] Perez, T., and Steinmann, P. "Analysis of ship roll gyrostabiliser control," in Proc. 8th IFAC Int. Conf. Manoeuv. Control Mar. Craft, Guarujá, Brazil, Sep. 16-18, 2009, pp. 310-315.

[5] Schlick, E.O., 1904a. Device for minimising the oscillatory movements of ships, Patent US769, 493.

[6] Schlick, E.O., 1904b. The gyroscopic effect of flywheels on board ship. Transactions of the Institute of Naval Architects 23, 117-134.

[7] Soong, T. T. (1990). "Active Structural Control: Theory and Practice", Longman Scientific and Technical, New York.

[8] Soong, T. T., and Dargush G. F. (1997). "Passive Energy Dissipation System in Structural Engineering", Wiley, New York.

[9] Soong, T. T., and Spencer, Jr., B. F. (2002). "Supplemental energy dissipation: state-of-the-art and state-of-the practice", Engineering Structures, 24 (3), 243-259.

[10] Spencer, B. F., Jr., and Sain, M. K. (1997). "Controlling buildings: A new frontier in feedback.” IEEE Control Syst. Mag., 17(6), 19-35.
[11] Spencer, B. F., Jr. (2002). "Civil engineering applications of smart damping technology.” Proc., 5th Int. Conf. on Vibration Engineering, Nanjing, China, 771-782.

[12] Townsend, N., Murphy, A., and Shenoi, R. "A new active gyrostabiliser system for ride control of marine vehicles," Ocean Eng., vol. 34, no. 11-12, pp. 1607-1617, Aug. 2007.

[13] Thornton, B., Ura, T., Nose, Y., and Turnock, S. "Internal actuation of underwater robots using control moment gyros," in Proc. IEEE OCEANS Conf., 2005, vol. 1, pp. 591-598.

[14] Ünker F, Çuvalcı O. Vibration Control of a Column Using a Gyroscope. Procedia - Social and Behavioral Sciences. 2015;195:2306-2315.

About Author (s):

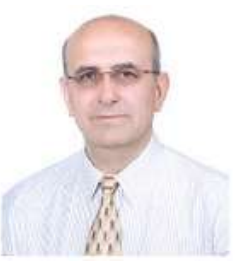

Olkan Çuvalcı is Professor at Karadeniz Technical University, in the Department of Mechanical Engineering. He received his B.Sc. and M.Sc. in Mechanical Engineering at the Karadeniz Technical University (KTU) in 1983 and 1985, respectively, and Ph.D. in Mechanical Engineering from Texas Tech University in 1992. From 1986-1993 he worked at KTU as a Research Assistant at the faculty of engineering. From 1996-1999 Çuvalcı worked as a research associate in Mechanical Engineering at Texas Tech University. From 1999-2000 he worked at the Western Kentucky University as an Associate Professor at the Engineering of Technology. In 1993, he became an Assistant Professor at KTU, in the Department of Mechanical Engineering. He was promoted to Associate Professor in 1995 and to Full Professor in 2012. From 2009-present he is also an Adjunct Professor at Texas Tech University. Professor Çuvalc1 is presently the Dean of Karadeniz Technical University's Faculty of Engineering. His several research interests lie at the intersections of control and optimization theory, Test Method Development, Experimental \& Theoretical Study of Nonlinear Dynamics, high-performance computing.

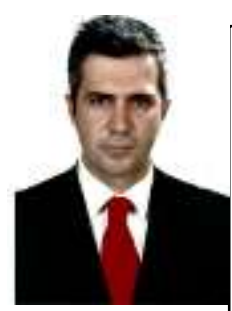

Faruk Ünker is currently a Research Assistant in Mechanical Engineering at Gümüşhane University. He received his BS and MS in Mechanical Engineering from Karadeniz Technical University (KTU) in 2007 and 2012, respectively. Faruk Ünker presently continues his $\mathrm{PhD}$ education at KTU. As a PhD student his research efforts have focused on Experimental \& Theoretical Study of Nonlinear Dynamics of gyroscopes. His industrial experience includes product design and development, manufacturing supervision, quality assurance and facility project coordination. He worked for an air-spring manufacturing company in Turkey as a Technical Service Engineer. 